\title{
Penerapan Internet Of Things (Iot) Sebagai Pengendali Peralatan Listrik Dan Pemantau Daya Listrik Berbasis Web
}

\author{
Syafriyadi Nor $^{1}$ \\ ${ }^{1}$ Politeknik Negeri Banjarmasin \\ Email : sapriyadi.yadi@gmail.com
}

\begin{abstract}
ABSTRAK
Penerapan teknologi Internet Of Thing (IoT) telah berkembang pesat, baik digunakan untuk aplikasi di industri maupun rumah tangga. Dengan penerapan teknologi IoT, peralatan listrik rumah tangga dapat dikendalikan secara otomatis melalui web, baik melalui internet maupun jaringan lokal. Interface web ini dapat mengatur kapan perangkat dinyalakan dan kapan dimatikan. Pembuatan webserver ini menggunakan bahasa HTML,PHP, dan Javascript. Internet of Things didefinisikan sebagai interkoneksi dari perangkat komputasi tertanam (embedded computing devices) yang teridentifikasi secara unik dalam keberadaan infrastruktur internet. Sistem kendali pada penelitian ini dirancang menggunakan Nodemcu ESP8266 12E sebagai pusat kendali dari sistem dan komunikasi kontroler ke internet melalui media wifi, serta modul Solid State Relay (SSR) guna sebagai saklar elektrik antara nodemcu dengan peralatan listrik dengan sumber PLN, sensor ZMPT101B sebagai sensor untuk membaca tegangan dari sumber PLN dan sensor ACS712 30 A sebagai sensor yang membaca arus listrik. Perangkat lunak pemrograman menggunakan arduino IDE. Hasil dari perancangan adalah sistem kontrol lampu atau peralatan listrik lainya yang dapat dikendalikan melalui web. Sistem pemantauan ini menggunakan layanan web hosting sebagai cloud database. Pengamatan dilakukan untuk mengetahui tingkat keberhasilan pengiriman data pemantauan. Perangkat didesain untuk mengirimkan data pemantauan setiap 1 detik. Hasil pengiriman menunjukkan data tegangan, arus, dan daya berupa grafik dan tabel pada web.
\end{abstract}

Kata kunci: Internet of Things, Nodemcu 8266 12E, sensor arus ACS712, sensor tegangan ZMPT101B dan Solid State Relay (SSR)

\section{PENDAHULUAN}

Jurusan Teknik Elektro Universitas Islam Kalimantan Muhammad Arsyad Al Banjari adalah jurusan pertama yang ada di kalimantan selatan. Jurusan teknik elektro mempelajari tentang ilmu di bidang informatika, elektronika dan listrik.

Sebagai mahasiswa jurusan teknik elektro di Universitas Islam Kalimantan Muhammad Arsyad Al Banjari, pemanfaatan ilmu pengetahuan dan teknologi yang didapat selama kuliah dapat diterapkan dan mengikuti perkembangan teknologi saat ini. Perkembangan teknologi tersebut ialah Internet of Things (IoT).

Berdasarkan uraian di atas penulis tertarik untuk menerapkan suatu bidang ilmu yang penulis dapat selama kuliah. Penulis membuat suatu alat yang dapat melakukan kegiatan pengendalian peralatan listrik dan pemantauan daya listrik. Untuk menerapkan sistem tersebut, maka salah satu aplikasi yang penulis buat sebagai skripsi adalah "Penerapan Internet Of Things (Iot) Dalam Pengendali Peralatan Listrik Dan Pemantau Daya Listrik 
Berbasis Web. Dengan sistem ini maka seseorang dapat mengendalikan peralatan listrik di rumah meski orang tersebut berada di tempat yang jauh. Pemantauan daya listrik dapat menampilkan data tegangan, arus dan daya yang terpasang. Selain pemantauan daya listrik dari web, data daya dari web juga dapat dijadikan acuan apabila seseorang ingin menghitung biaya listrik pada rumah sendiri.

\section{METODE}

Pada penelitian ini, peneliti ingin menyajikan perancangan hardware dan pemrogaman NodeMCU ESP8266 sebagai client untuk mengendalikan peralatan listrik rumah tangga seperti lampu, kipas angin, dan TV, serta memantau daya listrik.

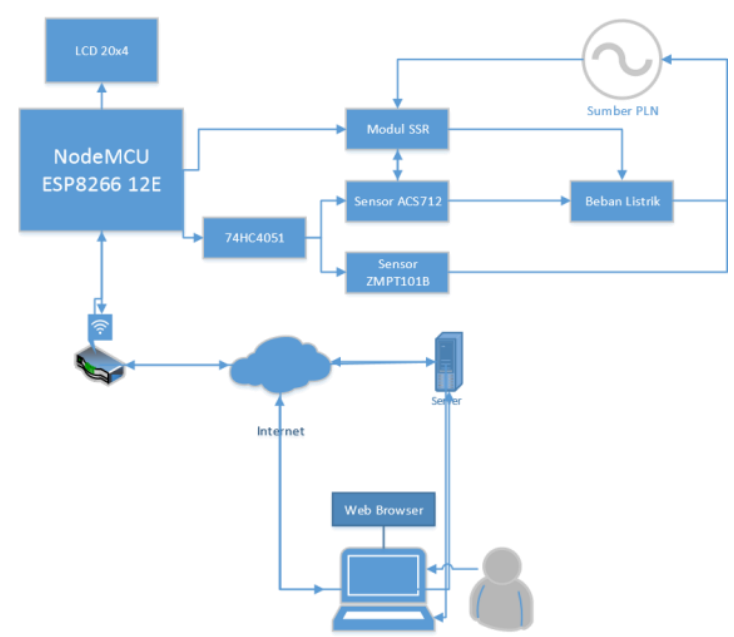

Gambar 1. Blok Diagram Sistem

NodeMCU ESP8266 merupakan pengendali utama pada Gambar 6. Modul ini sebagai client server, pengendali solid-state relay. Modul ini diprogram untuk bisa bekerja menjadi client server dengan terhubung internet.

Webserver yang berada pada webhosting dapat diakses pada komputer maupun smartphone. Pengguna dapat menentukan pengendalian suatu peralatan secara otomatis dengan web ini. Perancangan hardware ini meliputi pemilihan NodeMCU, solid-state relay, sensor arus ACS712, dan sensor tegangan ZMPT101B.

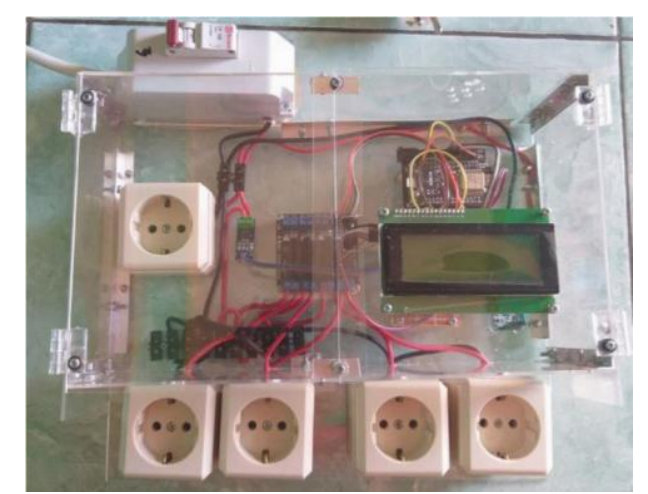

Gambar 2. Perangkat Pengendali dan Pemantau daya Listrik

\section{a. Pemrograman NodeMCU ESP8266}

Pada perancangan ini, peneliti membutuhkan packet library ESP8266 antara lain ESP8266WiFi dan LiquidCrystal_I2C. ESP8266WiFi digunakan untuk mengaktifkan WIFI sebagai mode Accespoint dan mode Station. LiquidCrystal_I2C digunakan untuk 
menampilkan data pada lcd dengan komunikasi i2c. ESP8266 ini dapat bekerja di 2 mode Accespoint (AP) maupun mode station. Pada mode AP, ESP8266 dapat terhubung dengan internet dengan interface dari router WIFI. Sedangkan pada mode mode Station, modul ini dapat dapat diakses langsung menggunakan perangkat elektronik seperti HP atau komputer. Pengendalian peralatan listrik dan pemantauan daya listrik. Pada pengendalian peralatan listrik, perangkat langsung dikendalikan hidup dan matinya melalui web. Sedangkan pemantauan daya yang dikirim dan disimpan kedalam database adalah tanggal, waktu, tegangan, arus dan daya, yang kemudian ditampilkan kedalam grafik dan tabel melalui antarmuka web. Pengiriman dan penerimaan data di atur selama 10 detik.

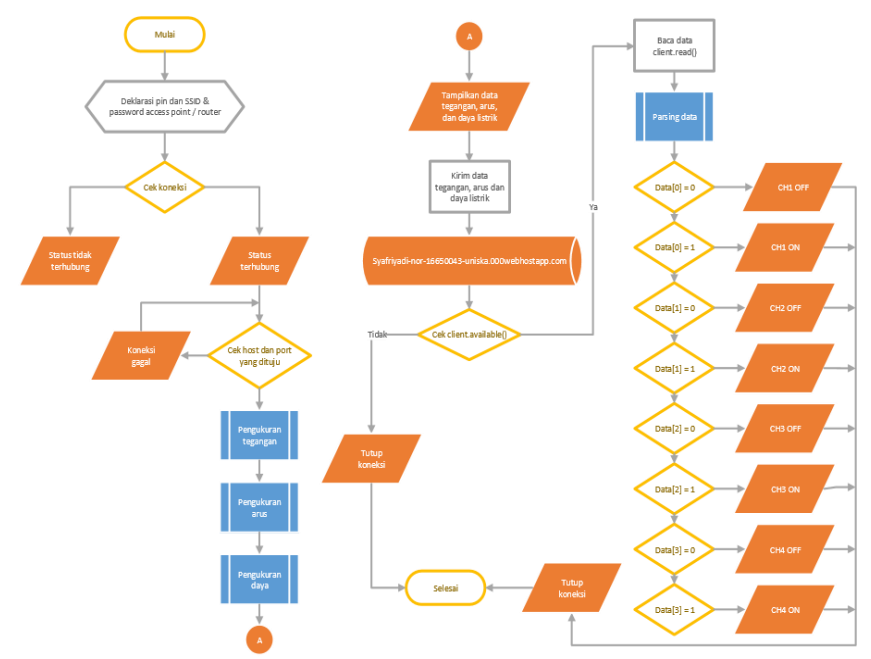

Gambar 3. Flowchart Program NodeMCU ESP8266

\section{b. Pemrograman Webserver}

Fasilitas yang digunakan untuk memprogram perangkat ini, adalah Windows 7 dengan aplikasi Arduino IDE. Dalam hal pemrogaman web, peneliti menggunakan progam Notepad++. Perintah PHP, Html dan Javascript dapat dicoba dulu pada aplikasi Notepad++, baik yang sederhana maupun yang kompleks. Setelah perintah berhasil, barulah perintah PHP, HTML dan Javascript diupload ke webhosting.

Web ini bertugas untuk mematikan dan menyalakan peralatan listrik. Web ini menampilkan status yang ditandai dengan warna merah untuk peralatan listrik menyala dan warna hijau untuk peralatan listrik mati.

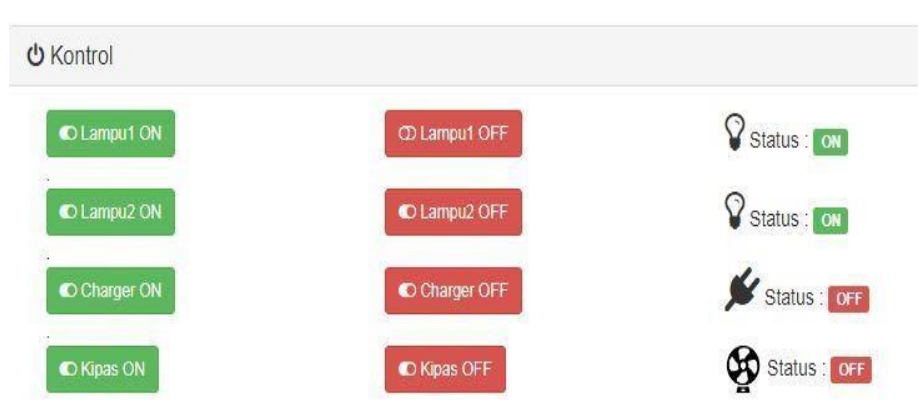

Gambar 4. Antarmuka Web untuk Pengendali peralatan Listrik

Pada web ini pemantauan daya listrik dapat ditampilkan berupa grafik dan tabel. Web ini dibuat dengan gabungan bahasa PHP, HTML dan Javascript. Program PHP bertugas untuk menyimpan data yang dikirimkan oleh NodeMCU kedalam database. Program Javascript dan HTML bertugas untuk membentuk tabel dan grafik. Program Javascript 
dibuat untuk membentuk grafik secara realtime dan tabel yang berisi data tanggal, waktu, tegangan, arus, dan daya listrik. Kemudian setiap 10 detik data akan diupdate seperti pada Gambar 5.

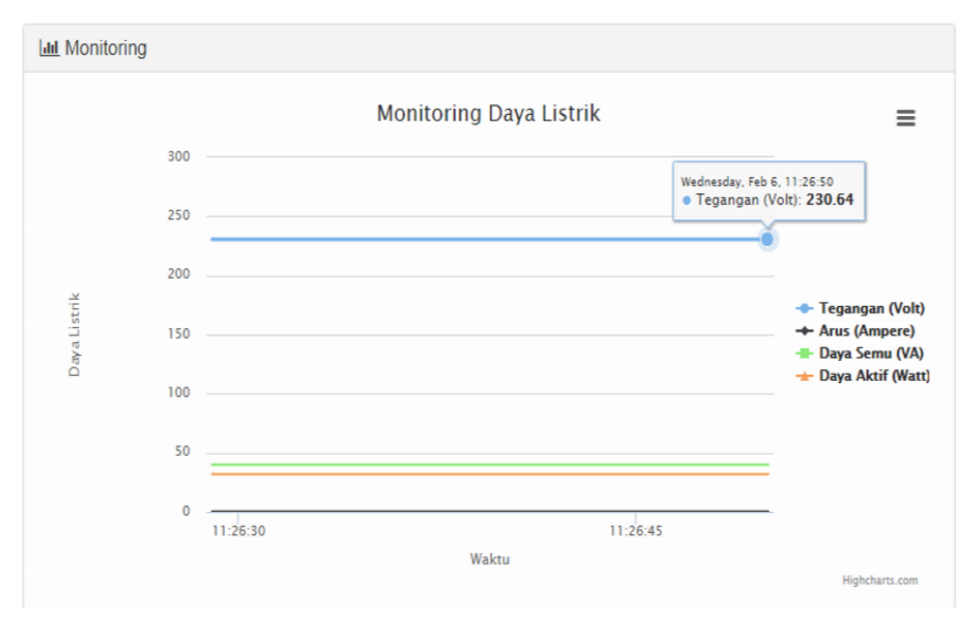

Gambar 5. Grafik Pemantauan Daya Listrik pada Web

\section{HASIL DAN PEMBAHASAN}

a. Pengujian pembacaan sensor dan pengukuran dengan multimeter

Pada pengujian ini, penulis membandingkan antara pembacaan sensor arus dan tegangan dengan menggunakan multimeter.

Tabel 1. Pembacaan Sensor dan Pengukuran Tegangan

\begin{tabular}{|c|c|c|c|}
\hline No & $\begin{array}{c}\text { Sumber } \\
\text { Tegangan }\end{array}$ & $\begin{array}{c}\text { Pengukuran } \\
\text { Multimetr Digital }\end{array}$ & $\begin{array}{c}\text { Pengukuran Sensor } \\
\text { ZMPT101B }\end{array}$ \\
\hline 1 & PLN & $229,1 \mathrm{~V}$ & $228,53 \mathrm{~V}$ \\
\hline
\end{tabular}

Tabel 2. Pembacaan Sesnor dan Pengukuran Arus

\begin{tabular}{|c|c|c|c|}
\hline No & Peralatan listrik & $\begin{array}{c}\text { Pembacaan } \\
\text { Sensor }\end{array}$ & $\begin{array}{c}\text { Pengukuran } \\
\text { Multimeter }\end{array}$ \\
\hline 1 & Lampu 7 Watt & $0,08 \mathrm{~A}$ & $0,09 \mathrm{~A}$ \\
\hline
\end{tabular}

Perbandingan ketiga pengukuran sensor tegangan, sensor arus dan multimeter mendapatkan hasil mendekati pengukuran yang hampir sama dapat dilihat pada Tabel 1 dan 2.

b. Pengujian Menampilkan Daya Listri Pada LCD

Pengujian lcd ini perlu dilakukan supaya daya listrik dapat ditampilkan sebelum dikirim ke web hosting. Selain itu peralatan listrik yang mana yang akan mati dan hidup. Pada Tabel 1 ditunjukkan bahwa pada saat pembacaan sensor tegangan dan arus ditampilkan pada lcd.

Tabel 3. Hasil Pengamatan pada LCD

\begin{tabular}{|l|l|l|l|l|l|}
\hline No & Beban Listrik & Tegangan & Arus & Daya & Daya \\
\hline
\end{tabular}




\begin{tabular}{|c|c|c|c|c|c|c|c|c|}
\cline { 2 - 5 } & CH 1 & CH 2 & $\begin{array}{l}\text { CH } \\
\mathbf{3}\end{array}$ & CH4 & (Volt) & (Amper) & $\begin{array}{c}\text { Semu } \\
\text { (VA) }\end{array}$ & $\begin{array}{c}\text { Aktif } \\
\text { (Watt) }\end{array}$ \\
\hline 1 & $\mathrm{X}$ & $\mathrm{X}$ & $\mathrm{X}$ & $\mathrm{X}$ & 230,65 & 0,03 & 7,964 & 6,3712 \\
\hline 2 & Lampu & $\mathrm{X}$ & $\mathrm{X}$ & $\mathrm{X}$ & 230,65 & 0,19 & 43,79 & 35,032 \\
\hline 3 & Lampu & Lampu & $\mathrm{X}$ & $\mathrm{X}$ & 230,65 & 0,33 & 75,64 & 60,512 \\
\hline 4 & Lampu & Lampu & $\begin{array}{c}\text { Kipas } \\
\text { Angin }\end{array}$ & $\mathrm{X}$ & 231,70 & 0,57 & 131,98 & 105,584 \\
\hline 5 & Lampu & Lampu & $\begin{array}{c}\text { Kipas } \\
\text { Angin }\end{array}$ & $\begin{array}{c}\text { Charger } \\
\text { HP }\end{array}$ & 231,70 & 0,59 & 135,98 & 108,784 \\
\hline
\end{tabular}

\section{c. Pengujian Web Server pada Webhosting}

Peralatan listrik dapat menyala atau mati dikendalikan oleh web baik. Pada Gambar 10 terlihat bahwa peralatan listrik akan menyala jika tombol on di klik. Pengaturan nyala dan mati dilakukan dengan memberikan nilai pada setiap field didalam tabel database. Pemberian warna merah menandakan bahwa nilai tersebut berlogika 0 dan warna hijau menandakan bahwa nilai nerlogika 1. Dari hasil pengujian didapatkan hasil bahwa konversi nilai string pada web ke dalam bilangan integer dapat dilakukan dengan memecah data kemudian disimpan dalam variabel integer. Hal ini dapat dilihat pada gambar 10.

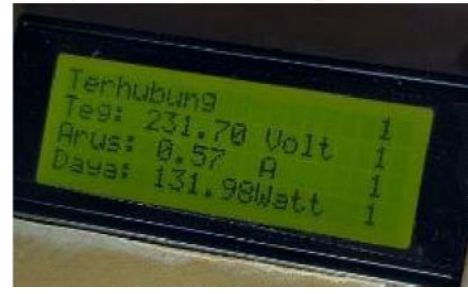

Gambar 6 Penerimaan data string menjadi integer

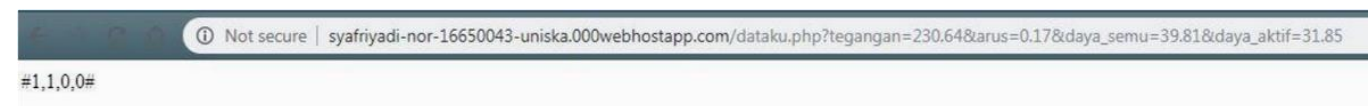

Gambar 7 Tampilan webserver saat mengirim data

Pada Gambar 6, terdapat alamat yang panjang yaitu http://syafriyadinor16650043uniska.000webhostapp.com/dataku.php?tegangan $=230.64 \&$ arus $=0.17 \&$ daya_se mu=39.81\&daya_aktif $=31.85$ merupakan nilai dari data tabel daya_listrik, nilai tegangan=230.64 adalah nilai data tegangan dst. Kemudian di dalam ESP8266, nilai tersebut ditampilkan pada lcd dan dikirimkan ke webserver. Nilai tadi disimpan dalam database, kemudian data daya akan ditampilkan berupa grafik dan tabel.

\section{PENUTUP}

Dari pengamatan yang dilakukan bahwa tegangan pada sumber PLN mengalami naik turun sehingga pembacaan data tegangan dan arus menjadi tidak stabil. Oleh karena itu telah dilakukan teknik pengambilan data dengan mendeteksi sinyal puncak dengan cara melakukan sampling pembacaan sensor sebanyak 1000 kali dengan interval tiap data selama $1 \mathrm{~ms}$. Dengan teknik tersebut pembacaan data menjadi stabil karena data yang terbaca hanya membaca data yang terbesar dari 1000 data lainya. Pengukuran tegangan dan arus oleh sensor dapat diolah menjadi data daya dengan cara memasukkanya kedalam suatu persamaan daya aktif yaitu, . 
Dalam melakukan pengukuran tegangan dari sumber PLN penulis mengukur tegangan yang terbaca oleh multimeter digital. Kemudian membandingkan pengukuran multimeter digital dengan pembacaan dari sensor. Hasilnya terdapat margin skitar 3-5 \%. Setiap beban atau peralatan listrik yang dihidupkan melalui web, pembacaan sensor arus mengalami kenaikkan tergantung dari beban yang dihidupkan. Jeda waktu yang dibutuhkan untuk mengirim dan menerima data selama 10 detik.

\section{REFERENSI}

A.Muhammad Syafar. 2016. Kendali Perangkat Listrik Dan Monitoring Daya Pada MCB Berbasis Tcp/Ip. Informatika Sains Dan Teknologi.

Alfiansyah, Elsa. 2009. "Rancang Bangun Sistem Monitoring Daya Listrik Pada Fotovoltaik Secara Realtime Berbasis Mikrokontroller Atmega 16", Skripsi, Departemen Teknik Elektro Fakultas Teknik Universitas Indonesia Depok.

Abubakar, S. N Khalid, M. W. Mustafa, Hussain Shareef and M. Mustapha. 2017. Calibration Of ZMPT101B Voltage Sensor Module Using Polynomial Regression For Accurate Load Monitoring. ARPN Journal of Engineering and Applied Sciences.

ACS712 Datasheet. https://www.allegromicro.com/ /media/files/datasheets/acs712datasheet.ashx. Diakses 3 Januari 2019

ESP8266 NodeMCU Wifi Module User Manual. https://www.handsontec.com/pdf_learn/esp8266-V10.pdf. Diakses 8 November 2018

Frizal Fitriandi, Endah Komalasari, Herri Gusmedi. 2016. Rancang Bangun Alat Monitoring Arus dan Tegangan Berbasis Mikrokontroller dengan SMS Gateway. Jurnal Rekayasa dan Teknologi Elektro.

Dwi Febrian Hendriyanto. 2019." Kajian Penggunaan Mikrotik Router OS Sebagai Router Pada Jaringan Komputer", Tugas Akhir, Fakultas Ilmu Komputer Jurusan Teknik Informatika Universitas Sriwijaya Palembang.

Fachri, Muhammad Rizal, Ira Devi Sara, dan Yuwaldi Away. 2015. "Pemantauan Parameter Panel Surya Berbasis

Arduino secara Real Time”. Jurnal Rekayasa Elektrika. Vol. 11 No. 4:123-128.

Hendra Saputra, Winasis, Azis Wisnu Widhi Nugraha. 2016. Perancangan Sistem Monitoring Enegri Listrik Panel Surya Berbasis Internet Of Things (ioT) Menggunakan Nodemcu. Pengembangan Sumber Daya Perdesaan dan Kearifan Lokal Berkelanjutan VI. 24-25.

Kussigit Santoso, Sudarno, Dedy Haryanto, 2014, Rancang Bangun Sistem Otomatisasi Katup Pada Untai Uji Beta Menggunakan Perangkat Lunak Labview. Sigma Epsilon. 18(3-4): 92

Krisianto, Andy. 2012. Panduan cPanel Web Hosting. Jakarta: PT Elex Media Komputindo

Kamajaya. 2008. Fisika. Bandung: Grafindo Media Pratama

Mochamad Fajar Wicaksono, Achmad Saeful Rohman. 2017. Backup Security pada Gedung Perkantoran Berbasis Arduino dan Android. Prosiding Seminar Nasional Komputer dan Informatika (SENASKI). 1-2. Bandung, - : UNIKOM.

Multiplexer 74HC4051 Datasheet. https://assets.nexperia.com/documents/datasheet/74HC_HCT4051.pdf. Diakses 27 Desember 2018

N, Muda, Imam. 2013. Elektronika Dasar. Malang: Gunung Samudera 
Nolvensius CH. Makasengghe, Benefit Narasiang, Sherwin R.U.A Sompie dan Bahrun. 2012. Perancangan Power Supply Digital Berbasis Mikrokontroller Menggunakan Keypad Sebagai Pemilih Tegangan. Jurnal Teknik Elektro dan Komputer.Vol 1(1): 2.

Rizki Priya Pratama. 2017. Aplikasi Webserver ESP8266 untuk Pengendali Peralatan Listrik. INVOTEK. 29(2): 39-40.

Rerung, Rante, Rintho. 2018. Pemrograman Web Dasar. Yogyakarta: CV Budi Utama

Salemba, Daud. 2013.” Monitoring dan Manajemen Data Pembangkit Listrik Tenaga Surya Berbasis Web", Tesis, Program Pasca Sarjana Universitas Hasanudin Makasar.

Saleh, Anang Supriadi dan Bahariawan, Amal. 2018. Energi \& Elektrifikasi Pertanian. Yogyakarta: DEEPUBLISH ( Group Penerbitan CV BUDI UTAMA)

Tri N., Fajar Suryo. 2016." Rancang Bangun Sistem Monitoring Daya Listrik dan Parameter Lingkungan Pada Sistem Photovoltaic Berbasis Internet of Things(IoT)", Tugas Akhir, Fakultas Teknik Jurusan Teknik Elektro Universitas Jenderal Soedirman Purwokwerto.

ZMPT101B Datasheet. https://www.plexishop.it/pdf/ZMPT101B\%20-\%20Datasheet.jpg.

Diakses 3 Januari 2019 